\title{
Rheumatoid arthritis in Latin America: the importance of an early diagnosis
}

\author{
Licia Maria Henrique da Mota $^{1}$ - Claiton Viegas Brenol ${ }^{2}$. \\ Penelope Palominos $^{3}$ • Geraldo da Rocha Castelar Pinheiro ${ }^{4}$
}

Received: 23 February 2015 /Revised: 10 April 2015 / Accepted: 17 May 2015 / Published online: 25 July 2015

(C) The Author(s) 2015. This article is published with open access at Springerlink.com

\begin{abstract}
The generalization of the early rheumatoid arthritis (ERA) concept and the existence of a window of therapeutic opportunity - a time span in which the institution of a proper therapeutic method for the disease would determine clinical improvement - have set the notion that early diagnosis and treatment may modify the course of the disease. Although in several regions of the world, especially in North America and Europe, since the year 2000, a significant reduction in diagnostic delay was observed in cohorts of patients with rheumatoid arthritis (RA), probably reflecting a stronger awareness of the importance of early diagnosis, this is not a reality in Latin America (LA). LA is a region of great economic inequality, with disparities in access to the public healthcare system and limited access to private medicine, being widely difficult to obtain a specialized medical evaluation in both scenarios. This paper aims to briefly review the main difficulties in the
\end{abstract}

Licia Maria Henrique da Mota

liciamhmota@gmail.com

1 Serviço de Reumatologia, Hospital Universitário de Brasília, Universidade de Brasília (UnB), Campus Universitário Darcy Ribeiro, Brasília, Distrito Federal 70910900, Brazil

2 Hospital de Clinicas de Porto Alegre, Universidade Federal do Rio Grande do Sul (UFRGS), Ramiro Barcelos 2350, Porto Alegre, Rio Grande do Sul CEP 90035-903, Brazil

3 Rheumatologist, Rheumatology Division, Hospital de Clinicas de Porto Alegre, Federal University of Rio Grande do Sul (UFRGS), Ramiro Barcelos 2350, Porto Alegre CEP 90035-903, Rio Grande do Sul, Brazil

4 Universidade Estadual do Rio de Janeiro, Boulevard 28 de Setembro, 77 sala 333 - CEP 20551-030 Rio de Janeiro,

Rio de Janeiro, Brazil management of ERA in LA, based on the review of the literature, on the evaluation of a survey conducted among 214 rheumatologists of LA, members of Pan-American League of Associations for Rheumatology (PANLAR) and the experience of the authors. The paper also aims to propose solutions to the difficulties in managing ERA in LA.

Keywords Early · Difficulties · Inequality · Latin America · Rheumatoid arthritis $\cdot$ Solutions

\section{Introduction}

Rheumatoid arthritis (RA) is an autoimmune, chronic inflammatory disease characterized by joint swelling, joint tenderness, and destruction of the synovial joints that can lead to severe disability and premature mortality. RA affects between 0.5 and $1 \%$ of the general population, mainly during their working age, affecting, thus, the functional capacity, with great economic burden to the individual and the society [1].

In the last decades, there was a clear evolution in knowledge about physiopathology of the disease, resulting in changes in its approach and treatment. The association between symptom duration and RA persistence is not linear, suggesting the presence of a confined period in which RA is more susceptible to treatment [2].

Early RA (ERA) is defined as the diagnosis given in the first weeks or months of joint symptoms or signs. The generalization of the ERA concept and the existence of a window of therapeutic opportunity - a time span in which the institution of a proper therapeutic method for the disease would determine clinical improvement - have set the notion that early diagnosis and treatment may modify the course of the disease [3].

Currently, evaluating a patient with articular symptoms in the first possible opportunity is aimed at, and the definition of the 
RA's early stage comprises the first weeks or months of symptoms (generally less than 12 months), the first 12 weeks of manifestations with very early rheumatoid arthritis (VERA) standing out as a critical period. Those patients with more than 12 weeks and less than 12 months of articular symptoms are included in what is known as late early rheumatoid arthritis (LERA) [4].

Concomitantly, laboratory and imaging methods were improved or developed, contributing to an earlier diagnosis and determination of prognostic for early RA [5]. In the last two decades, RA's treatment has undergone intense changes, reflecting both the modification of the therapeutic approach paradigm and the introduction of new classes of diseasemodifying anti-rheumatic drugs (DMARDs), including biological response modifiers (biological therapy) [6].

In this context, early arthritis recognition clinics (EARC) and ERA clinics have been established in some countries in recent decades, in order to receive early and offer appropriate treatment for patients within the first months of disease evolution, including medical follow-up by the rheumatologist and, ideally, multidisciplinary care [7].

Despite these progresses, it is well known that the limiting factor to a good therapeutic response is still the delay in diagnosis and in the institution of the adequate treatment, as well as the difficulty in handling the medication during the patient's follow-up [8].

Although in several regions of the world, especially in North America and Europe, since the year 2000, a significant reduction in diagnostic delay was observed in cohorts of patients with RA, probably reflecting a stronger awareness of the importance of early diagnosis, this is not a reality in Latin America (LA) [9-12].

LA and the Caribbean, a rapidly growing region with almost 600 million inhabitants composed of Mexico, Central and South America, and the islands of the Caribbean, is one of the most unequal regions in the world, according to the Economic Commission for Latin America and the Caribbean (United Nations) [13, 14]. People from different LA countries have little access to private medicine and disparities in access to the public healthcare system, with widespread difficulty to obtain specialized medical attention in both.

This paper aims to briefly review the main difficulties in the management of ERA in LA, based on the review of the literature, the evaluation of a survey conducted among Latin American rheumatologists members of Pan-American League of Associations for Rheumatology ) and the experience of the authors. The paper also aims to propose solutions to the difficulties in managing ERA in LA.

\section{Materials and methods}

We searched PubMed, Lilacs (Latin American and Caribbean Literature on Health Sciences), and Scielo (Scientific
Electronic Library Online) using terms related to early arthritis and, in PubMed, combining them with country names or regional names related to Latin American and the Caribbean Islands. The search strategy for PubMed was: (early arthritis OR recent onset arthritis) AND ("Latin America" OR "Central America" OR "South America" OR "Caribbean" OR "Argentina" OR "Bolivia" OR "Brazil" OR "Chile" OR "Colombia" OR "Costa Rica" OR "Cuba" OR "Dominican Republic" OR "Ecuador" OR "El Salvador" OR "Guatemala" OR "Haiti" OR "Honduras" OR "Mexico" OR "Nicaragua" OR "Panama" OR "Paraguai" OR "Peru" OR "Uruguay" OR "Venezuela"). In Lilacs, we preceded two searches, using the terms "early arthritis" and "early rheumatoid arthritis." To search through Scielo, we used the terms "early arthritis" (without quotes) and "recent onset arthritis." Articles were selected when they approached early arthritis clinic or management of early arthritis in Latin America and the Caribbean.

Aiming to know the panorama of the difficulties relating to the management of ERA in LA, a survey was conducted among members of PANLAR. The questionnaire was forwarded by e-mail to all members of PANLAR, containing, among other evaluations, 20 specific questions about ERA. Several themes were addressed, including the existence or not of ERA clinics or EARC in the region (and the country), the definition of ERA (duration of symptoms), the system of reference from basic assistance, and the main difficulties for access of patients to diagnostic and therapeutic management. It was also requested from rheumatologists possible solutions to the problems raised.

Some of the questions were multiple choice, while others demanded detailed answers. The questionnaire is available as Appendix 1.

\section{Results}

A total of 438 articles were identified through the online search: 304 in PubMed, 33 in Lilacs, and 106 in Scielo. Some of them were excluded as duplicates and most were excluded after screening title. Around 50 articles were selected to full-text reading and 13 were used as references for this paper.

Two hundred and fourteen rheumatologists, from different LA countries, answered the survey. Table 1 summarizes the responses of Latin American rheumatologists to multiple-choice questions. Table 2 present aspects of the current reality found on the Latin American countries, listing the challenges and proposed solutions for resolving the difficulties observed, based on the interpretation of the questionnaire applied (detailed answers) regarding the importance of the early diagnosis of RA in this region. 
Table 1 Summary of the responses of rheumatologists to multiplechoice questions to know the panorama of the difficulties relating to the management of ERA in LA

\begin{tabular}{l} 
Early rheumatoid arth \\
\hline Questions \\
In there any \\
ERA or early \\
arthritis clinic \\
in your practice? \\
\\
If the answer to \\
the first question \\
is negative, where \\
ERA or early \\
arthritis patients \\
are evaluated? \\
If the answer to the \\
first question is \\
positive, how long \\
does it exist?
\end{tabular}

To be considered ERA, how long symptoms need to be present?

In your practice, do you use any classification criteria for diagnosis of ERA?

In your outpatient care, how many patients are you following with ERA?

\footnotetext{
How many professionals work in the
} ERA clinic?
Table 1 (continued)

Early rheumatoid arthritis scenario in Latino America

\begin{tabular}{|c|c|c|}
\hline & Rheumatologists & $171(93.96)$ \\
\hline & Residents & $77(42.31)$ \\
\hline & $\begin{array}{l}\text { Physicians } \\
\text { (not rheumatologists) }\end{array}$ & $20(10.99)$ \\
\hline & Nurses & $38(20.88)$ \\
\hline & Occupational therapists & $31(17.03)$ \\
\hline & Administrative staff & $25(13.74)$ \\
\hline & Other & $30(16.48)$ \\
\hline \multirow{5}{*}{$\begin{array}{c}\text { How is the access } \\
\text { of the patients } \\
\text { to ERA clinic? }\end{array}$} & Free access & $95(48.47)$ \\
\hline & $\begin{array}{l}\text { Referral by general } \\
\text { practitioners }\end{array}$ & $122(62.24)$ \\
\hline & $\begin{array}{l}\text { Referral by } \\
\text { rheumatologists }\end{array}$ & $29(14.80)$ \\
\hline & More than one above & $52(26.53)$ \\
\hline & Other & $8(4.08)$ \\
\hline \multirow{2}{*}{$\begin{array}{l}\text { Is there any endemic } \\
\text { disease in your } \\
\text { country important } \\
\text { for differential } \\
\text { diagnosis of RA? }\end{array}$} & Yes & $31(15.35)$ \\
\hline & No & $171(84.65)$ \\
\hline \multirow{6}{*}{$\begin{array}{l}\text { What composite } \\
\text { score do you } \\
\text { use in your } \\
\text { practice? }\end{array}$} & DAS28 & $192(94.58)$ \\
\hline & HAQ & $116(57.14)$ \\
\hline & SDAI & $27(13.30)$ \\
\hline & CDAI & $54(26.60)$ \\
\hline & None & $5(2.46)$ \\
\hline & Other & $12(5.91)$ \\
\hline \multirow{4}{*}{$\begin{array}{l}\text {-What questionnaire } \\
\text { of quality of life } \\
\text { do you use in } \\
\text { your practice? }\end{array}$} & HAQ & $179(90.40)$ \\
\hline & MHAQ & $13(6.57)$ \\
\hline & RAPID & $25(12.63)$ \\
\hline & Other & $8(5.05)$ \\
\hline \multirow{4}{*}{$\begin{array}{l}\text { What kind of } \\
\text { treatment patients } \\
\text { are using in your } \\
\text { practice? }\end{array}$} & Glucocorticoids & $105(51)$ \\
\hline & $\begin{array}{l}\text { Non steroidal } \\
\text { anti-inflammatories }\end{array}$ & $125(61)$ \\
\hline & Synthetic DMARDs & $179(87)$ \\
\hline & Biologic DMARDs & $20(10)$ \\
\hline \multirow{5}{*}{$\begin{array}{l}\text { How often do } \\
\text { patients with ERA } \\
\text { visit the physician? }\end{array}$} & Once in a month & $57(29.23)$ \\
\hline & Every 3 months & $99(50.77)$ \\
\hline & Every 6 months & $12(6.15)$ \\
\hline & Once in a year & $4(2.05)$ \\
\hline & Other & $23(11.79)$ \\
\hline
\end{tabular}


Table 2 The importance of early diagnosis of rheumatoid arthritis - current reality, challenges, and proposed solutions

\begin{tabular}{ll}
\hline Current reality & Challenges \\
\hline $\begin{array}{l}\text { There are few structured clinics for screening } \\
\text { (capitation?) and follow-up of patients in the }\end{array}$ & $\begin{array}{l}\text { Creation/establishment of clinics with } \\
\text { appropriate structure to receive early } \\
\text { early phase of arthritis or RA }\end{array}$ \\
$\begin{array}{l}\text { on, diagnose and treat early arthritis, } \\
\text { both in public or private services }\end{array}$
\end{tabular}

- Lack of medical professionals

(rheumatologists) on the existing clinics

- Shortage of other healthcare professionals (nurses, occupational therapists, physiotherapists, physical educators, psychologists, social workers, nutritionist) and supporting staff (secretaries) at the existing clinics

- Patients' difficulty of access to arthritis clinics or early arthritis clinics, both on public and private services

- Patient lateness in seeking health assistance

*Geographical factors (great distancespatients that reside in rural areas, far away from centers where there are rheumatologists)

*Cultural factors (fear of the diagnosis, belief in a "serious and incurable disease")

*Social and economical factors (lack of resources for transportation or access to the doctor on the private system)

* Self-medication (frequent use, with free access, and no prescription, of antiinflammatory drugs and corticosteroids)

* Delay on the referral from other specialists (general practitioners, orthopedists)

*Inexistence of an adequate reference/counter reference system

*Lack of vacancies for the appointment of new cases

- Difficulties to diagnose RA

- Restricted general access to additional tests (such as inflammatory activity tests, rheumatoid factor and ACPA) and some image exams (ultrasonography and magnetic resonance imaging) on public services, and high cost on private services

- Lack of diagnosis protocols

- Difficulties for the differential diagnosis:

- Occurrence of other infectious conditions that have differential diagnosis with RA (Chikungunya fever, Hansen's disease, dengue fever, CMV, parvovirus B19, HIV, viral hepatitis, tuberculosis)

- Frequently limited access to viral serology and other tests for differential diagnosis

- Non application or non existence of protocols for treating early RA

- Allocate rheumatologist to outpatient early arthritis or early rheumatoid arthritis clinics

Proposed solutions

- Establishment of guidelines (and guides) for the implementation of early arthritis clinics in each service (by the local rheumatology associations basing themselves on successful experiences on the region itself)

- Awareness of the population, health managers, and government on the importance of the early diagnosis and the existence of specific structures for diagnosis and follow-up

- Establish healthcare policies, on public and private services, that recognize the importance of allocating rheumatologists in reference units to diagnose and follow-up on early arthritis;

- Continuing medical education ofrheumatologists and engagement in early RA clinics - Designate healthcare professionals of
correlate
areas for the care of patients with early
arthritis or early RA

- Establishment, on RA patients' follow-up protocols, of the importance of multidisciplinary follow-up

- Engaging of other professionals for patient follow-up

Optimize patients' access to reference centers for diagnosis and treatment of early RA

- Reducing the time between the onset of symptoms and the assessment by the rheumatologist

- Improve the level of knowledge on RA of the general practitioner and of other correlated specialist

- Broaden the access to additional tests eventually necessary for the differential diagnosis, both on public and private healthcare services
- Broaden the access to additional tests and image exams eventually necessary for the differential diagnosis, both on public and private healthcare services

- Educational campaigns for the patient (information on the alert symptoms of RA and on the importance of the early diagnosis/treatment)

- Education and training of general practitioners and orthopedists (adequate training of general practitioners, general internists, and allied health symptoms and the creation of EAC or areas within rheumatology units to provide care for patients referred early in the course of their disease)

- Inclusion of information on arthritis on the medical course (graduation)

- Establishment of a efficient system of reference/ counter reference that allows the referral of a patient by the general practitioners or orthopedist in a timely fashion, with a posterior referral to the primary health care unit, after controlling the disease

- Establishment of local protocols (regional associations of rheumatology, hospital services protocols) for early diagnosis of RA

- Inclusion of additional tests in the public services paying lists and the private paying sources

\footnotetext{
- Inclusion of possible endemic-epidemic diseases on Latin America as possible differential diagnosis for the initial arthritis cases

- Inclusion of the necessary additional tests for differential diagnosis in the public services paying lists and the private paying sources
}

- Many of the existing protocols and guidelines, including the local Latin American associations' professionals in articular examination and RA 
Table 2 (continued)

\begin{tabular}{lcc}
\hline Current reality & Challenges & Proposed solutions \\
\hline $\begin{array}{l}\text { - Difficulty of access to synthetic and } \\
\text { biological medication }\end{array}$ & $\begin{array}{c}\text { - Dissemination and application of the } \\
\text { existing protocols, or creation of } \\
\text { regional protocols for treating early RA } \\
\text { - Extend the access to synthetic medication } \\
\text { and, when necessary, biological }\end{array}$ & $\begin{array}{l}\text { protocols, already contemplate treatment for } \\
\text { early RA, being necessary a greater dissemination } \\
\text { of those among rheumatologists and correlated } \\
\text { specialists. }\end{array}$ \\
& & $\begin{array}{c}\text { - Inclusion of DMARD in the public } \\
\text { services paying lists and the private paying } \\
\text { sources, with emphasis on the importance of early } \\
\text { therapy }\end{array}$ \\
$\begin{array}{l}\text { - Difficulty to maintain an adequate periodicity } \\
\text { between appointments due to lack of } \\
\text { professionals and vacancies }\end{array}$ & $\begin{array}{c}\text { - Implementation of circumstances that } \\
\text { enable the creation of new vacancies } \\
\text { on existing early arthritis clinics }\end{array}$ & - Establishment of an effective counter reference \\
system for discharge of patients followed at early & RA clinics
\end{tabular}

\section{Discussion}

According to Community Oriented Program for Control of Rheumatic Diseases (COPCORD) methodology, musculoskeletal (MSK) complaints in the last 7 days, unrelated to trauma, are common but vary among different populations [15]. In LA countries, the prevalence of MSK complaints was as low as $9.3 \%$ in Guatemala [15-17], 25.5 to $27.1 \%$ in Mexico [15, 18-20], 26.9 to $30.9 \%$ in Brazil [15, 21, 22], and as high as $43.9 \%$ in Cuba [15, 23], $45.1 \%$ in Chile [15], and $46.5 \%$ in Peru [15]. In most studies, a higher prevalence of pain unrelated to trauma was detected among females [15].

Ideally, patients with recent onset of MSK pain should be seen by a primary care physician (PCP) (general practitioner-GP). On the other hand, in the presence of signs or symptoms of systemic or inflammatory disease, these patients should promptly be referred to a rheumatologist. The proportion of rheumatologists that have the opportunity of evaluating a patient in the first 6 weeks of symptoms has gone from $9 \%$ in 1997 to $17 \%$ in 2003, although not all of the cases may be evaluated so quickly [24].

Unfortunately, the early referral to a rheumatologist is not what usually happens in most, if not all LA countries $[25,26]$. This might be due to several reasons:

(1) Most people do not realize that "rheumatism" is a vague term that encompasses many diseases with different treatment and prognosis, so they are not aware that the first thing they need to do is to have a diagnosis to explain their MSK condition;

(2) Many people do not have easy access to the healthcare system, delaying the medical evaluation;

(3) Most patients with MSK pain are referred by the GP to the specialist without a specific referral criteria (most patients with common diseases such as osteoarthritis, fibromyalgia, and mechanical low back pain should not be referred to a rheumatologist but followed by a GP);
(4) Many GP do not readily identify the patients with inflammatory conditions delaying the proper referral to the specialist;

(5) There are few rheumatologists in the secondary or tertiary healthcare system so it usually takes some time for this specialist's appointment;

(6) Most, if not all, rheumatology outpatients clinics do not have a triage system or a "fast track agenda" for early arthritis patients (early arthritis clinic-EAC) so even those patients need to wait to be seen.

Early recognition and treatment with DMARDs is important in achieving control of disease and prevention of joint injury and disability - this strategy is associated with improved clinical and radiographic outcome. The first 12 weeks of symptoms, in particular, are a critical period called as "very early RA" (VERA) and represents the best chance to achieve a complete remission and to stop the erosive course of RA [27-29]. Not all patients meet the criteria for RA at the early stages of the disease. In clinical practice, all cases of arthritis that cannot be classified in one of the accepted categories are referred as "undifferentiated arthritis" (UA). In one third of patients with recent onset arthritis, it is not possible to come to a definitive diagnosis at presentation. Among these cases, approximately $30 \%$ will progress to RA [30]. The others may have alternative definitive diagnoses such as infections, spondyloarthritis, other systemic rheumatic diseases, microcrystalline arthropathies, osteoarthritis, or others; may also evolve into remission or even remain as UA $[30,31]$.

There seems to be, however, a consensus among LA key opinion leaders rheumatologists about the importance of early diagnosis for the proper management of RA by rheumatologists [24-27]. There is evidence of systematic differences between rheumatologists and non-rheumatologists in early recognition and in initiating the use of DMARDs for treatment of RA. Non-rheumatologists generally delay treatment, resulting 
in worse outcomes of the disease [32] RA patients were diagnosed earlier, receive DMARD therapy more frequently and achieved better clinical and radiographic outcomes when managed by rheumatologists [32-35]. To the best clinical and functional prognosis of patients with RA, it is recommended that the primary care physician refer briefly suspected cases to the rheumatologist [36]. Despite this, the average time for the first visit of RA patients with a rheumatologist is 17 and 19 months to elapse before the first administration of DMARDs [37].

The diagnosis of RA is established considering clinical findings and complementary examinations. No isolated test, laboratory, imaging or histopathological, confirms the diagnosis alone.

There have also been "proposed actions" to increase the early suspicion, the proper diagnoses of RA, and right and rapid referral of these patients to the rheumatologists [38]. Among other ideas, it was proposed an adequate training of general practitioners, general internists, and allied health professionals in articular examination and RA symptoms and the creation of EAC or areas within rheumatology units to provide care for patients referred early in the course of their disease.

The gap between recognition of symptoms, diagnosis, and treatment is dependent at least from four steps: from the patient at symptom onset to assessment in primary care, from primary care provider (PCP) to rheumatology referral, from rheumatology referral to assessment and from rheumatology assessment to commencement of DMARD therapy. Several strategies have been studied with the aim of reducing the interval between each of these four steps, including the training of primary care physicians for the early recognition and referral of suspected cases of RA, self-administered questionnaires, triage of referrals, triage clinics and early arthritis clinics (EACs) [39].

Only few studies carried out with Latin American populations on the demographic and clinical characteristics of patients diagnosed with ERA can be found in the literature.

GLADAR (Grupo Latino Americano de Estudio de Artritis Reumatoide) was a large, multicenter, multinational inception cohort of Latin American patients. Consecutive patients with ERA $(<1$ year of disease duration as diagnosed by a rheumatologist) from 46 centers in 14 Latin American countries were enrolled in GLADAR. Clinical data, laboratory assessments, and a detailed registry on type of prescription of 1093 patients were collected at baseline and at 3, 6, 12, 18, and 24 months of follow-up. GLADAR has issued some guidelines for the pharmacological treatment of RA that promote an early aggressive therapy. Early disease clinics are established in some LAC countries. The GLADAR experience has shown that most early RA patients (i.e., $<1$ year of disease duration) receive methotrexate [40-42].

CONAART (Consorcio Argentino de Artritis TempranaArgentine Consortium for Early Arthritis) is an initiative of seven rheumatology centers across Argentina. Patients were included if they had at least one or more swollen joints and $<2$ years of disease duration. A total of 413 patients were included. From CONAART data, we know some social, demographic, familiar, hereditary, clinical, and laboratory data from Argentine ERA patients [43]. CONAART also informed about work disability and its main associated factors in patients with ERA [43]. They also analyzed the effects of cigarette smoking on disease activity, functional capacity, radiographic damage, serology, and presence of extra-articular manifestations in patients not only with ERA, but also with undifferentiated arthritis, and found that neither was tobacco exposure related to the presence of extra-articular manifestations or to the degree of disability in any of the two groups of patients [44].

The Brasilia Cohort of RA is an incident cohort of patients with early RA, followed in the Outpatient Rheumatology Clinic of Hospital Universitário de Brasília, Universidade de Brasília. For inclusion in this cohort, early RA is defined as the occurrence of joint symptoms compatible with pain and joint swelling with an inflammatory pattern, with or without morning stiffness or other manifestations suggestive of inflammatory joint disease, assessed by a single observer, lasting more than 6 weeks and less than 12 months, regardless of meeting the criteria of the American College of Rheumatology (ACR). All selected patients retrospectively met the EULAR/ACR criteria 2010. From the moment of diagnosis, patients are followed prospectively, and receive the standard treatment regimen used in Brazil, including synthetic or biological DMARDs, according to their needs. Patients are monitored in accordance with the principles of Treat to Target, and the medication adjusted to achieve remission. Currently, there are 132 patients accompanied by protocol form for up to 11 years, from the initial diagnosis. From Brasilia Cohort, we have information about demographic, clinical, laboratorial and radiographic characteristics of patients enrolled in this Brazilian cohort, disease activity, and impact on quality of life. Other aspects also have been studied by Brasilia Cohort, including, for example, physical activity practice among patients with early RA and the possible association between physical activity, disease activity and functional disability, frequency of vaccination, and the orientation about vaccines among patients in Brasilia Cohort [45-49].

Solutions are needed to offer patients with inflammation of the small joints - with a high likelihood of having rheumatoid arthritis - to be seen quickly and receive treatment in a timely fashion. For early recognition and management of RA, efforts must be composed mainly of medical education and health system organization. As a feasible example in LA, a network for early diagnosis and management of arthritis was implemented adopting several strategies: primary care providers education, use of referral algorithms, creation of a rapid access system to an early arthritis clinic (EAC) and institution of a 
task force to reduce the waiting list for rheumatologist assessment. Through an initiative involving Primary and Tertiary Public Health Care Centers in the South of Brazil, general practitioners were capacitated to recognize and provide early referral to patients with arthritis and an EAC was created to offer prompt evaluation of newly referred patients. The project was composed by two steps: medical training workshops for PCPs focused on early recognition and referral of patients with arthritis and the creation of an EAC for prompt treatment of newly referred patients. Several workshops for primary care physicians training were conducted in an University Hospital in South of Brazil, the Hospital de Clínicas de Porto Alegre (HCPA). Each workshop lasted $4 \mathrm{~h}$ and on each session, three rheumatologists from HCPA ministered theoretical lesions which included several themes: concept and etiology of early UA, importance of early referral to rheumatologist to optimize outcomes, consequences of RA on function and quality of life, the algorithm for early referral proposed by the European League against Rheumatic Diseases (EULAR) [36], the use of DMARDs, focusing on methotrexate use, and the prevention and management of comorbidities in patients with RA. Each workshop also included a practical lesson where physicians assessed disease activity in RA by using composite scores: the Disease Activity Score 28 joints (DAS 28) [50] and the Clinical Disease Activity Index (CDAI) [51]. Fifteen students from Medicine School/Federal University of Rio Grande do Sul (UFRGS) were trained and participated as monitors during the practical lessons. Physicians participating in workshops were invited to visit the RA clinic in HCPA to have contact with RA patients, learning to recognize the presence of arthritis on physical exam. Additionally, a Clinic for Assessment and Treatment of Early Arthritis was created in a Tertiary Health Center (HCPA) after negotiations with the Municipal Health Office. Since then, four clinical consultations are offered each week for patients with early arthritis referred from PCPs. Patients referred to this clinic are seen in a timely fashion (2-4 weeks) because they are not sent to the usual referral system. The project allowed better recognition of patients with early arthritis and decreased referrals of patients who could be managed in primary care. The work is ongoing and was partially funded by PANLAR.

In Mexico, Sánchez et al. described the prevalence of dyslipidemia, serum lipid behaviour, and predictors of serum lipid levels in a cohort of 146 Mexican mestizo ERA patients [52].

Although there are not many publications on early RA clinics in Latin America, we do know that there are rheumatology services that maintain clinics with this purpose. On a survey performed among Latin American rheumatologists, with an Internet questionnaire sent by PANLAR, from 214 rheumatologists who responded this survey, 13.2 and $20.1 \%$, respectively, informed that ERA clinics or EARC do exist in their services.
A common pattern for social policies was developed in most Latin American countries, rooted in a similar development model and responsible for some of the most remarkable features of the relationship between the state and the society, as well as for incorporating a particular power structure into a formalized system. The general characteristics of this pattern were identified in the health sector as: the segmentation and/or exclusion of groups of the population; the fragmentation of the institutions; the narrow and fragile financial basis of the system, mainly based on contributions upon salaries, and the existence of strong actors with vested interests represented in this political arena. In spite of these similarities, it is indispensable to highlight the variations among the countries, concerning the way they faced this critical period and the effects of the adjustment policies on their recovery [53]. Generally, the public health system in LA countries serves the entire population. In the usual referral system, general practitioners can refer patients to specialists in a hospital setting or specialized outpatient clinic. Since there are few rheumatologists in the public system, patients have to wait their turn for the availability of a rheumatology consultation. This process takes months and, sometimes, even years. For patients with RA, this delay may represent the loss of the window of opportunity for therapeutic intervention.

On LA, just as in other regions of the world, the costs related with RA are elevated. Spending on RA patients assume greater impact in developing countries, where financial resources for health are less robust. This emphasizes the importance of studies assessing the costs and the allocation of resources. The diagnosis of RA in the initial phase is extremely important because appropriate treatment early in the disease can change the natural history of this condition.

The answers to the survey applied to the Latin American rheumatologists, we conclude that, despite the recognized importance, in LA, not only economic, but also linguistic, cultural, social, and gender barriers can present challenges and barriers for the healthcare system and its policy for the treatment and health access in the context of ERA.

This gives us a picture of the overall setting in which the health system reforms are being carried out and how it changes RA care access. We should also add data concerning the resources for health systems, to have a better representation of the possibilities and constraints in realizing the health system reforms, specifically in terms of ERA care policy.

Acknowledgments The authors thank all rheumatologists who responded to the survey sent via the web, and to PANLAR, by sending questionnaires.

Disclosures None. 


\section{Appendix 1}

\section{Rheumatoid Arthritis in Latin America}

\section{Section 1 . The importance of early diagnosis}

1. Is there a specialized early arthritis clinic or rheumatoid arthritis clinic in your service?

( ) Yes, there is an early rheumatoid arthritis clinic.

( ) No

( ) Yes, there is an early arthritis clinic.

Other (specify)

2. If the answer for the first question was negative, where are patients with early rheumatoid arthritis or early arthritis evaluated in your service?

( ) In the established rheumatoid arthritis outpatient clinic

( ) Other (specify)

3. If the answer for the first question was positive, for how long is there an early arthritis clinic or early rheumatoid arthritis clinic?
( ) $<1$ year
( ) Between 1 and 3 years
( ) Between 3 and 5 years
( ) Between 5 and 10 years
( ) More than 10 years
( ) Other (specify)

4. What is the duration of symptoms to be considered early rheumatoid arthritis in your service?
( ) Less than 12 weeks
( ) Less than 1 year
( ) Less than 2 years
( ) Less than 3 years
( ) Less than 5 years
( ) Other (specify)

5. In your service, is a classification criterion used to define patients with early rheumatoid arthritis?

( ) No, it is considered the clinical diagnosis of arthritis by a physician, regardless of classification criteria

( ) Yes, we use the 1987 ACR classification criteria

( ) Yes, we use the 2010 ACR-EULAR classification criteria

( ) Other (specify) 
6. How many patients are currently being followed in the early rheumatoid arthritis clinic from your service?

( ) Less than 50 patients

( ) Between 50 and 100 patients

( ) Between 100 and 200 patients

( ) More than 200 patients

( ) Approximate number if more than 200:

7. How many people are involved in the care of patients in the early rheumatoid arthritis clinic from your service?

( ) Teachers

( ) Rheumatologists doctors

( ) Residents

( ) Non-rheumatologist doctors (specify):

( ) Nurses

( ) Occupational Therapist

( ) Secretaries

( ) Other (specify)

8. How is the access of early rheumatoid arthritis patients to the clinic of your service?

( ) The demand is free - spontaneous patient demand

( ) Referral by general practitioner or other specialist

( ) Referral by rheumatologists

( ) More than one option

( ) Other (specify)

9. *What are the main difficulties of access of patients to the early rheumatoid arthritis clinic from your service?

10. *What are the main difficulties in diagnosing patients (delay for the first evaluation, difficulties in laboratory tests - specify)

11. Is there any common endemic disease in your area that is routinely considered in the differential diagnosis of rheumatoid arthritis in your service?

( ) Yes

( ) No

If yes, what is it? 
12. *How is the treatment of patients from the early rheumatoid arthritis clinic of your service?

Then specify a specific protocol

13. Which of the composite indices of disease activity are used in monitoring patients?
( ) DAS 28
( ) HAQ
( ) SDAI
( ) CDAI
( ) None
( ) Other (specify)

14. What quality of life or disability questionnaires are used?
( ) HAQ
( ) MHAQ
( ) RAPID
( ) Other (specify)

15. Are there difficulties in obtaining medicines for the treatment of patients in the early rheumatoid arthritis clinic from your service? Specify:

16. *What approximate percentage of patients in the early rheumatoid arthritis clinic is currently using?

Corticosteroids

Non-steroidal anti-inflammatory

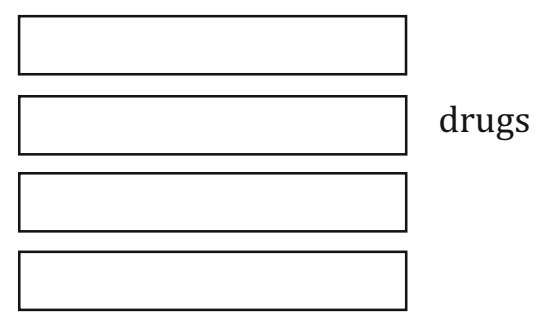

Synthetic DMARD

Biological DMARD

17. On average, how often a patient is evaluated in the early rheumatoid arthritis clinic of your service?
( ) Once a month
( ) Once every three months
( ) Once every six months
( ) Once a year
( ) Other (specify) 
18. *What is the length of stay of patients in the early rheumatoid arthritis clinic of your service? Are they kept untracked in early rheumatoid arthritis clinic or referred to other clinics?

19. *What are the main difficulties for the functioning of the early rheumatoid arthritis clinic in your service?

20. *What would be the main proposals to improve the functioning of the early rheumatoid arthritis clinic in your service?

\section{Rheumatoid Arthritis in Latin America}

\section{Section 2. Treatment guidelines}

1. Are you aware of any rheumatoid arthritis treatment guidelines?

( ) Yes

( ) No

If yes, please list the 3 that you know best:

S

2. Do you use any rheumatoid arthritis treatment guidelines?
( ) Yes
( ) No

3. If you answered yes, please indicate which guidelines you use.

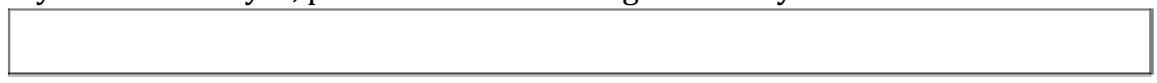

4. In what percentage of patients with RA do you think that the guidelines are NOT

applicable?

10

20

30

40

50 or more

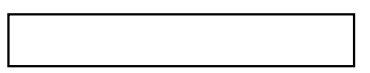

5. Which of the following barriers do you face to implement rheumatoid arthritis treatment guidelines? You can check more than one option.

( ) Lack of knowledge about the guidelines

( ) They are not practical in the management of the individual patient

( ) They are not updated

( ) Lack of patient access to medications

( ) I do not agree with the guidelines

( ) Other (specify) 


\section{Rheumatoid Arthritis in Latin America}

3. Section 3. Human resources and health system

1. * Has your National Scientific Society a census or survey, over the past 5 years, on the amount and distribution of rheumatologists?

( ) Yes

( ) No

If yes, please indicate date of the census/survey: _ / _ / _ _ _ and how many rheumatologists are active:

2. Are rheumatologists mostly concentrated in big cities $(>100,000)$ ?

( ) Yes

( ) No

( ) I do not know

Comments

3. Are there areas where the population has no access to a rheumatologist or rheumatology service?

( ) Yes

( ) No

Comments

4. Are there public hospitals in 2nd or 3rd level with no rheumatologists?
( ) Yes
( ) No

5. Is there public access to rheumatologists or rheumatology services free of charge in public hospitals for the entire population?
( ) Yes
( ) No

6. Are there formal referral systems for medical or health workers of the 1st level (primary health care, PHC) to a rheumatologist or rheumatology service?
( ) Yes
( ) No

7. Are there counter-referral systems? (When the patient is formally derived, with its diagnosis and treatment, from the rheumatologist or the rheumatology service to the effectors of the 1st level of care (PHC).)
( ) Yes
( ) No

8. Is there postgraduate training for the specialty of rheumatology?
( ) Yes
( ) No
Comments 


\section{Rheumatoid Arthritis in Latin America}

\section{Section 4. Treatments}

1. In your country, is there access to the following treatments?

\begin{tabular}{|l|l|l|}
\hline \multicolumn{1}{|c|}{ Pharmacological treatments } & Yes & \\
\hline Prednisone & & \\
\hline Methotrexate & & \\
\hline Leflunomide & & \\
\hline Sulfasalazine & & \\
\hline Antimalarials & & \\
\hline Anti-TNF- $\alpha$ & & \\
\hline Abatacept & & \\
\hline Rituximab & & \\
\hline Tocilizumab & & \\
\hline Tofacitinib & & \\
\hline
\end{tabular}

2. Please complete the following table on the cost and the percentage of coverage by health systems of the available drugs in your country. Should not be available for some health system, place ND.

\begin{tabular}{|l|l|l|l|l|}
\hline & $\begin{array}{c}\text { Monthly Cost } \\
\text { (US \$) }^{(1)}\end{array}$ & $\begin{array}{c}\text { \% coverage by } \\
\text { Public Sector(2) }\end{array}$ & $\begin{array}{c}\text { \% coverage by } \\
\text { Social } \\
\text { Security(2) }\end{array}$ & $\begin{array}{c}\text { \% coverage by } \\
\text { private } \\
\text { insurance(2) }\end{array}$ \\
\hline Drug & & & & \\
\hline Prednisone & & & & \\
\hline Methotrexate & & & & \\
\hline Leflunomide & & & & \\
\hline Sulfasalazine & & & & \\
\hline Chloroquine & & & & \\
\hline Anti-TNF- $\alpha$ & & & & \\
\hline Abatacept & & & & \\
\hline Rituximab & & & & \\
\hline Tocilizumab & & & & \\
\hline
\end{tabular}


Tofacitinib

(1): $0-500 ; 501-1000 ; 1001-1500 ; 1501-2000 ;>2000$

(2): $0-10 \% ; 11-20 \% ; 21-30 \%$; 31-40\%; 41-50\%; 51-60\%; 61-70\%; 71-80\%; 81-90\%; $91-$ $100 \%$

Comments

3. How would you rate the difficulty $(0-10)$ for the prescription of these drugs in the following health systems? (Where 0 is no difficulty and 10 is impossible to prescribe.)

\begin{tabular}{|l|l|l|l|}
\hline & Public Sector & Social Security & Private insurance \\
\hline Prednisone & & & \\
\hline Methotrexate & & & \\
\hline Leflunomide & & & \\
\hline Sulfasalazine & & & \\
\hline Chloroquine & & & \\
\hline Anti-TNF- $\alpha$ & & & \\
\hline Abatacept & & & \\
\hline Rituximab & & & \\
\hline Tocilizumab & & & \\
\hline Tofacitinib & & & \\
\hline
\end{tabular}

Other (specify)

4. Do you think that rheumatologists mostly exercise the "Treat to Target" and "Tight Control" to achieve remission of the disease?
( ) Yes
( ) No

Comments 
Open Access This article is distributed under the terms of the Creative Commons Attribution 4.0 International License (http:// creativecommons.org/licenses/by/4.0/), which permits unrestricted use, distribution, and reproduction in any medium, provided you give appropriate credit to the original author(s) and the source, provide a link to the Creative Commons license, and indicate if changes were made.

\section{References}

1. Aletaha D, Neogi T, Silman AJ et al (2010) 2010 rheumatoid arthritis classification criteria. An American College of Rheumatology/European League against rheumatism collaborative initiative. Arthritis Rheum 62:2569-2581. doi:10.1002/art.27584

2. van Nies JA, Tsonaka R, Gaujoux-Viala C, Fautrel B, van der Helmvan Mil AH (2015) Evaluating relationships between symptom duration and persistence of rheumatoid arthritis: does a window of opportunity exist? Results on the leiden early arthritis clinic and ESPOIR cohorts. Ann Rheum Dis. doi:10.1136/annrheumdis-2014-206047

3. van der Horst-Bruinsma IE, Speyer I, Visser H, Breedvelt FC, Hazes GM (1998) Diagnosis and course of early-onset arthritis: results of a special early arthritis clinic compared to routine patient care. Br J Rheumatol 37:1084-1088

4. Nell VPK, Machold KP, Eberl G, Stamm TA, Uffmann M, Smolen JS (2004) Benefit of very early referral and very early therapy with disease-modifying anti-rheumatic drugs in patients with early rheumatoid arthritis. Rheumatology 43:906-914

5. Nam JL, Ramiro S, Gaujoux-Viala C, Takase K, Leon-Garcia M, Emery P, Gossec L, Landewe R, Smolen JS, Buch MH (2014) Efficacy of biological disease-modifying antirheumatic drugs: a systematic literature review informing the 2013 update of the EULAR recommendations for the management of rheumatoid arthritis. Ann Rheum Dis 73(3):516-528. doi:10.1136/annrheumdis-2013-204577

6. Majithia V, Geraci SA (2007) Rheumatoid arthritis: diagnosis and management. Am J Med 120:936-939

7. van Nies JA, Brouwer E, van Gaalen FA, Allaart CF, Huizinga TW, Posthumus MD, van der Helm-van Mil AH (2013) Improved early identification of arthritis: evaluating the efficacy of early arthritis recognition clinics. Ann Rheum Dis 72(8):1295-1301. doi:10. 1136/annrheumdis-2012-202289

8. Cabral D, Katz JN, Weinblatt ME, Ting G, Avorn J, Solomon DH (2005) Development and assessment of indicators of rheumatoid arthritis severity: results of a Delphi panel. Arthritis Rheum 53:61-66

9. Sørensen J (2015) Hetland ML, on behalf of all departments of rheumatology in Denmark (2014) diagnostic delay in patients with rheumatoid arthritis, psoriatic arthritis and ankylosing spondylitis: results from the Danish nationwide DANBIO registry. Ann Rheum Dis 74(3), e12. doi:10.1136/annrheumdis-2013-204867

10. Sokka T, Kautiainen H, Pincus T, Toloza S, da Rocha Castelar Pinheiro G et al (2009) Disparities in rheumatoid arthritis disease activity according to gross domestic product in 25 countries in the QUEST-RA database. Ann Rheum Dis 68(11):1666-1672. doi:10. 1136/ard.2009.109983

11. Uhlig T, Heiberg T, Mowinckel P et al (2008) Rheumatoid arthritis is milder in the new millennium: health status in patients with rheumatoid arthritis 1994-2004. Ann Rheum Dis 67:1710-1715

12. Raza K, Stack R, Kumar K et al (2011) Delays in assessment of patients with rheumatoid arthritis: variations across Europe. Ann Rheum Dis 70:1822-1825

13. Cecchini S, Martínez R (2012) Inclusive social protection in Latin America: a comprehensive, rights-based approach. Libros de la CEPAL No.111, 2012. http://repositorio.cepal.org/bitstream/
handle/11362/2596/S1100566_en.pdf?sequence=1. Accessed 12 February 2015.

14. Gattini C, Ruiz Health in South America 2012 Edition Health Situation, Policies and Systems Overview. Health Information and Analysis Project (HSD/HA) Country Focus Support Office (CFS) Pan American Health Organization World Health Organization http://new.paho.org/chi/images/PDFs/health\%20in\%20sam $\%$ 202012\%20\%28jan.13\%29.pdf. Accessed 10 February 2015

15. Chopra A, Abdel-Nasser A (2008) Epidemiology of rheumatic musculoskeletal disorders in the developing world. Best Pract Res Clin Rheumatol 22:583-604

16. Chopra A (2012) The WHO ILAR COPCORD Latin America: consistent with the world and setting a new perspective. J Clin Rheumatol 18:1679

17. Chopra A (2013) The COPCORD world of musculoskeletal pain and arthritis. Deeply rooted in the community. Rheumatology 52: 1925-1928. doi:10.1093/rheumatology/ket222

18. Bennett K, Cardiel MH, Ferraz MB, Riedemann P, Goldsmith CH, Tugwell P (1997) Community screening for rheumatic disorder: cross cultural adaptation and screening characteristics of the COPCORD core questionnaire in Brazil, Chile, and Mexico. The PANLAR-COPCORD working group. Pan American League of Associations for rheumatology. community oriented programme for the control of rheumatic disease. J Rheumatol 24(1):160-168

19. Peláez-Ballestas I, Sanin LH, Moreno-Montoya J, AlvarezNemegyei J, Burgos-Vargas R, Garza-Elizondo M, RodríguezAmado J, Goycochea-Robles MV, Madariaga M, Zamudio J, Santana N, Cardiel MH, Grupo de Estudio Epidemiológico de Enfermedades Músculo Articulares (GEEMA) (2011) Epidemiology of the rheumatic diseases in Mexico. A study of 5 regions based on the COPCORD methodology. J Rheumatol Suppl 86:3-8. doi:10.3899/jrheum.100951, Erratum in: J Rheumatol Suppl. 2011 Mar;38(3):585

20. Rodriguez-Amado J, Peláez-Ballestas I, Sanin LH, EsquivelValerio JA, Burgos-Vargas R, Pérez-Barbosa L, Riega-Torres J, Garza-Elizondo MA (2011) Epidemiology of rheumatic diseases. A community-based study in urban and rural populations in the state of Nuevo Leon, Mexico. J Rheumatol Suppl 86:9-14. doi: 10.3899/jrheum. 100952

21. Senna ER, De Barros AL, Silva EO, Costa IF, Pereira LV, Ciconelli RM, Ferraz MB (2004) Prevalence of rheumatic diseases in Brazil: a study using the COPCORD approach. J Rheumatol 31(3):594-597

22. Pereira AM, Valim V, Zandonade E, Ciconelli RM (2009) Prevalence of musculoskeletal manifestations in the adult Brazilian population: a study using copcord questionnaires. Clin Exp Rheumatol 27(1):42-46

23. Reyes-Llerena GA, Guibert-Toledano M, Penedo-Coello A, PérezRodríguez A, Baez-Dueñas RM, Charnicharo-Vidal R, Cardiel MH (2009) Community-based study to estimate prevalence and burden of illness of rheumatic diseases in Cuba: a COPCORD study. J Clin Rheumatol 15(2):51-55. doi:10.1097/RHU.0b013e31819b61cb

24. Aletaha D, Eberl G, Nell VP, Machold KP, Smolen JS (2004) Attitudes to early rheumatoid arthritis: changing patterns. Results of a survey. Ann Rheum Dis 63:1269-1275

25. Pinheiro GRC, Rebello MA, Andrade DO et al (2003) Investigating the role of rheumatologists in musculoskeletal disease management in the city of Rio de Janeiro. Ann Rheum Dis 62:534

26. Xibillé-Friedmann D, Mondragón-Flores V, Horcasitas de la Rosa C (2006) Criteria used by primary care physicians for the diagnosis and referral to a rheumatologist of patients with rheumatoid arthritis. Reumatol Clin 2(5):235-238

27. Lard LR, Visser H, Speyer I, vander Horst-Bruinsma IE, Zwinderman AH, Breedveld FC et al (2001) Early versus delayed treatment in patients with recent-onset rheumatoid arthritis: comparison of two cohorts who received different treatment strategies. Am J Med 111(6):446-451 
28. Nell VP, Machold KP, Eberl G, Stamm TA, Uffmann M, Smolen JS (2004) Benefit of very early referral and very early therapy with disease-modifying anti-rheumatic drugs in patients with early rheumatoid arthritis. Rheumatology (Oxford) 43(7):906-914

29. Bosello S, Fedele AL, Peluso G, Gremese E, Tolusso B, Ferraccioli G (2011) Very early rheumatoid arthritis is the major predictor of major outcomes: clinical ACR remission and radiographic non-progression. Ann Rheum Dis 70(7):1292-1295

30. Verpoort KN, van Dongen H, Allaart CF, Toes RE, Breedveld FC, Huizinga TW (2004) Undifferentiated arthritis - disease course assessed in several inception cohorts. Clin Exp Rheumatol 5(Suppl 35):12-17

31. van Aken J, van Dongen $\mathrm{H}$, le Cessie S, Allaart CF, Breedveld FC, Huizinga TW (2006) Comparison of long term outcome of patients with rheumatoid arthritis presenting with undifferentiated arthritis or with rheumatoid arthritis: an observational cohort study. Ann Rheum Dis 65(1):20-25

32. Criswell LA, Such CL, Yelin EH (1997) Differences in the use of second-line agents and prednisone for treatment of rheumatoid arthritis by rheumatologists and non-rheumatologists. J Rheumatol 24(12):2283-2290

33. Lacaille D, Anis AH, Guh DP, Esdaile JM (2005) Gaps in care for rheumatoid arthritis: a population study. Arthritis Rheum 53(2): 241-248

34. Rat AC, Henegariu V, Boissier MC (2004) Do primary care physicians have a place in the management of rheumatoid arthritis? Joint Bone Spine 71(3):190-197

35. Solomon DH, Bates DW, Panush RS, Katz JN (1997) Costs, outcomes, and patient satisfaction by provider type for patients with rheumatic and musculoskeletal conditions: a critical review of the literature and proposed methodologic standards. Ann Intern Med 127(1):52-60

36. Emery P, Breedveld FC, Dougados M, Kalden JR, Schiff MH, Smolen JS (2002) Early referral recommendation for newly diagnosed rheumatoid arthritis: evidence based development of a clinical guide. Ann Rheum Dis 61(4):290-297

37. Hernandez-Garcia C, Vargas E, Abasolo L, Lajas C, Bellajdell B, Morado IC et al (2000) Lag time between onset of symptoms and access to rheumatology care and DMARD therapy in a cohort of patients with rheumatoid arthritis. J Rheumatol 27(10):2323-2328

38. Cardiel MH, Latin American Rheumatology Associations of the Pan-American League of Associations for Rheumatology (PANLAR), Grupo Latino Americano de Estudio de Artritis Reumatoide (GLADAR) (2006) First Latin American position paper on the pharmacological treatment of rheumatoid arthritis. Rheumatology (Oxford) 45(Suppl:i):7-22

39. Villeneuve E, Nam JL, Bell MJ, Deighton CM, Felson DT, Hazes JM et al (2013) A systematic literature review of strategies promoting early referral and reducing delays in the diagnosis and management of inflammatory arthritis. Ann Rheum Dis 72(1):13-22

40. Massardo L, Suárez-Almazor ME, Cardiel MH, Nava A, Levy RA, Laurindo I, Soriano ER, Acevedo-Vázquez E, Millán A, PinedaVillaseñor C, Galarza-Maldonado C, Caballero-Uribe CV, Espinosa-Morales R, Pons-Estel BA (2009) Management of patients with rheumatoid arthritis in Latin America: a consensus position paper from Pan-American League of Associations of Rheumatology and Grupo Latino Americano De Estudio De Artritis Reumatoide. J Clin Rheumatol 15(4):203-210. doi:10. 1097/RHU.0b013e3181a90cd8

41. Massardo L, Pons-Estel BA, Wojdyla D, Cardiel MH, GalarzaMaldonado CM, Sacnun MP, Soriano ER, Laurindo IM, AcevedoVásquez EM, Caballero-Uribe CV, Padilla O, Guibert-Toledano ZM, da Mota LM, Montufar RA, Lino-Pérez L, Díaz-Coto JF, AchurraCastillo AF, Hernández JA, Esteva-Spinetti MH, Ramírez LA, Pineda C, Furst DE (2012) Early rheumatoid arthritis in Latin America: low socioeconomic status related to high disease activity at baseline. Arthritis Care Res 64(8):1135-1143. doi:10.1002/acr.21680
42. Cardiel MH, Pons-Estel BA, Sacnun MP, Wojdyla D, Saurit V, Marcos JC, Pinto MR, Cordeiro de Azevedo AB, da Silveira IG, Radominski SC, Ximenes AC, Massardo L, Ballesteros F, RojasVillarraga A, Oñate RV, Hernandez MP, Esquivel-Valerio JA, García-De La Torre I, Khoury VJ, Millán A, Soriano ER, GLADAR (2012) Treatment of early rheumatoid arthritis in a multinational inception cohort of Latin American patients: the GLADAR experience. J Clin Rheumatol 18(7):327-335. doi:10. 1097/RHU.0b013e31826d6610

43. Marcos J, Waimann C, Dal Pra F, Hogrefe J, Retamozo S, Caeiro F, Casalla L, Benegas M, Rillo O, Spindler A, Berman H, Berman A, Secco A, García Salinas R, Catalán Pellet A, Ceccato F, Paira S, Marcos JC, Maldonado Cocco JA, Citera G, CONAART (Consorcio Argentino de Artritis Temprana-Argentine Consortium for Early Arthritis) (2011) General characteristics of an early arthritis cohort in Argentina. Rheumatology (Oxford) 50(1):110-116. doi:10.1093/rheumatology/keq220

44. Haye Salinas MJ, Retamozo S, Alvarez AC, Maldonado Ficco H, Dal Pra F, Citera G, Benegas M, Chaparro Del Moral R, Rillo O, Secco A, Marino Claverie L, Catalan Pellet A, Marcos J, García MA, Marcos JC, Barbaglia A, Bellomio V, Berman A, Quiroz C, Soriano ER, Ceccato F, Paira S, Vazquez D, Juarez VR, Velozo EJ, Salvatierra G, Caeiro F (2014) Effects of cigarette smoking on early arthritis: a cross-sectional study-data from the Argentine Consortium for Early Arthritis (CONAART). Rheumatol Int 35(5):855-859

45. da Mota LM, Laurindo IM, dos Santos Neto LL (2010) Demographic and clinical characteristics of a cohort of patients with early rheumatoid arthritis. Rev Bras Reumatol 50(3):235-248

46. da Mota LM, Dos Santos Neto LL, Oliveira AC, Pereira IA, Burlingame RW, Ménard HA (2012) Laurindo IM (2012) Baseline HAQ and SF-36 questionnaire scores cannot predict clinical remission, radiographic progression or the need for biological therapy in a three-year prospective study of a Brazilian early rheumatoid arthritis cohort. Rheumatol Int 32(12):3937-3943. doi:10. 1007/s00296-011-2261-8

47. Mota LM, Santos Neto LL, Burlingame RW, Ménard HA, Pereira IA, Carvalho JF, Laurindo IM (2012) Disability and quality-of-life are not influenced by the prevalence of autoantibodies in early rheumatoid arthritis patients - results of the Brasília Cohort. Rev Bras Reumatol 52(6):824-829

48. Silva CR, Costa TF, de Oliveira TT, Muniz LF, da Mota LM (2013) Physical activity among patients from the Brasília cohort of early rheumatoid arthritis. Rev Bras Reumatol 53(5):394-399

49. Muniz LF, Silva CR, Costa TF, da Mota LM (2014) Vaccination in patients from Brasília cohort with early rheumatoid arthritis. Rev Bras Reumatol 54(5):349-355. doi:10.1016/j.rbr.2014.04.002

50. Prevoo ML, van't Hof MA, Kuper HH, van Leeuwen MA, van de Putte LB, van Riel PL (1995) Modified disease activity scores that include twenty-eight-joint counts: development and validation in a prospective longitudinal study of patients with rheumatoid arthritis. Arthritis Rheum 38:44-48

51. Aletaha D, Nell VP, Stamm T, Uffmann M, Pflugbeil S, Machold K et al (2005) Acute phase reactants add little to composite disease activity indices for rheumatoid arthritis: validation of a clinical activity score. Arthritis Res Ther 7(4):R796-R806

52. Sánchez T, Contreras-Yáñez I, Elías-López D, Aguilar Salinas CA, Pascual-Ramos V (2014) Prevalence of lipid phenotypes, serum lipid behaviour over follow-up and predictors of serum lipid levels in a cohort of Mexican Mestizo early rheumatoid arthritis patients treated with conventional disease-modifying anti-rheumatic drugs. Clin Exp Rheumatol 32(4):509-515

53. Fleury S. Reshaping Latin-American health care systems: toward fairness? http://lasa.international.pitt.edu/lasa98/Fleury.pdf. Accessed 09 February 2015. 